\title{
Established criteria for disease controlling drugs in ankylosing spondylitis
}

\section{D Gladman}

\section{The ASAS recommendations for the initiation of DC -ART in AS are a good start}

A nkylosing spondylitis (AS) is primarily an inflammatory arthritis of the back, affecting the sacroiliac and apophysial joints. ${ }^{1}$ The age of onset is usually late teens with men being affected nine times more than women. Onset is gradual with pain and stiffness in the low back, characteristically at night or early morning. ${ }^{2}$ The natural history of AS is progression to affect the whole spine, resulting in spinal deformities. These include flattening of the lumbar lordosis, kyphosis of the thoracic spine, and hyperextension of the cervical spine, with eventual flexion contractures of the hips and knees and significant morbidity and disability. These clinical features are mirrored by the radiological changes of syndesmophytes and ankylosis of the spine as well as erosive changes, sclerosis, and eventual ankylosis of the sacroiliac joints. ${ }^{3}$

Peripheral arthritis occurs uncommonly in AS, and when it occurs, it is usually late in the course of the arthritis. ${ }^{4}$ The development of peripheral arthritis early in the course of the disease is a predictor of disease progression. ${ }^{5}$ The arthritis usually presents in the lower extremities in an asymmetric distribution. Involvement of the "axial" joints, including shoulders and hips, is more common than involvement of more distal joints. In the shoulder, there may be a unique lesion of erosion at insertion of the rotator cuff. ${ }^{6}$ In the hips, progressive flexion deformity and eventual destruction of the joint may occur. In addition, enthesitis, or inflammation at sites of tendon insertion into bone, is common, affecting primarily plantar fascia and Achilles tendon insertion. The disease is often complicated by the presence of iritis (particularly anterior uveitis), cardiac manifestations (including dilatation of the root of the aorta and conduction defects) , fibrosis of the upper lobes of the lungs, cauda equina syndrome (which results from multiple thecal diverticulae or dilated lumbar sacs), and later in the course of the disease, amyloidosis. ${ }^{7}$

Longitudinal studies in patients with AS have shown that the deformities and disability occur within the first 10 years of disease. ${ }^{4}$ Survival is reduced among patients with AS compared with the general population, with a relative risk of 1.93. Causes of death include heart disease, cerebrovascular disease, malignancy, renal failure, pneumonia, and miscellaneous. Thus AS is not a benign condition.

\section{TREATMENT IN AS}

Treatment in AS is directed primarily at symptom relief-that is, control of pain and stiffness. The mainstay of treatment in AS is exercise to alleviate stiffness and maintain mobility, and non-steroidal anti-inflammatory drugs (NSAIDs) to control the inflammatory symptoms. Although there is some evidence that exercises work to relieve symptoms of $\mathrm{AS}^{8}{ }^{8}$ there is no evidence that progression of deformity and disability are slowed down. ${ }^{9}$ In the short term NSAIDs have been shown to improve pain and range of movement, but there is no evidence that they possess disease modifying effect. ${ }^{10}$

\section{"N SAIDs improve pain and range of movement but do not modify the disease"}

Moreover, a proportion of patients with AS do not respond to these conservative measures and have a protracted course, which results in deformity and disability. Sulfasalazine has been used as a disease controlling agent with benefit in some trials, ${ }_{11}^{11}$ but the most recent and largest trial failed to demonstrate improvement in the spinal disease. ${ }^{12}$ Evidence for the efficacy of other systemic drugs, including methotrexate, corticosteroids, D-penicillamine, auranofin, and azathioprine, is inconclusive. ${ }^{13}$

\section{NEW BIOLOGICAL TREATMENTS}

The advent of biological treatment has provided promise for patients with AS. Recent studies have shown that antiTNF agents alleviate both symptoms and signs of inflammation in patients with
AS. ${ }^{14-18}$ Indeed, in AS, biological treatment may be considered to be the first line treatment after NSAIDs. ${ }^{18}$ Although these drugs appear relatively safe in the short term, there is concern about their long term toxicity. M oreover, these drugs are expensive, and indeed unavailable in some countries. Therefore, criteria for the judicious use of such treatment in patients with AS are necessary so that treatment is provided to appropriate patients.

\section{CRITERIA FOR THE USE OF BIOLOGICAL AGENTS}

Based on review of evidence

Criteria for the use of drugs may be based on a review of evidence, or based on expert opinion. The first approach to the use of anti-tumour necrosis factor $\alpha$ (anti-TNF $\alpha$ ) agents in the treatment of spondyloarthritis was undertaken by the SpondyloArthritis Research Consortium of Canada (SPARCC). ${ }^{13}$ The group re viewed available drug treatment and graded the evidence according to the level: A, based on randomised controlled trials; B, based on clinical studies without randomisation; $C$, based on expert committees' opinions, experiences, or post-marketing surveillance and regulatory agencies recommendations. Based on the review of the evidence recommendations were made to the Canadian Rheumatology Association (CRA) where consensus was sought and obtained. The resultant recommendations were that anti-TNF $\alpha$ agents may be used after a full trial of at least two NSAIDs has been shown to be inadequate- that is, lacking either efficacy or tolerability. All therapeutic options should be equally available according to the best judgment of the treating doctor and informed decision of the patient. It was recommended that drugs should not be denied on the basis of economic considerations.

\section{Based on expert opinion}

The Assessment in Ankylosing Spondylitis (ASAS) group took the expert opinion approach to tackle the recommendations for the use of disease controlling, especially biological treatment, in AS. ${ }^{19}$ ASAS is an international group of people interested in AS, who have worked for several years now to establish assessment instruments for AS, and have advanced the study of $A S$ and its recognition as a major form of arthritis. ASAS developed recommendations for considering initiation of disease controlling antirheumatic treatment (DC-ART), in particular antiTNF treatment. ${ }^{20}$ Unlike the SPARCC method, the ASAS recommendations are based on expert opinion using a Delphi study. Thus, 32 of the 62 members of ASAS participated in three stages of a Delphi process, whereby they initially identified the features of an AS patient 
considered for DC-ART. The list of 128 items relating to peripheral arthritis and 99 to axial disease were assigned to domains, which were subsequently reduced in a second round and identified as domains relevant to peripheral arthritis, axial disease, and enthesitis. In the third phase specific instruments to define the domains were identified, and finally, the group formulated the ASAS preliminary recommendations for considering initiation of DC-ART, particularly anti-TNF agents in AS.

\section{"Recommendations for starting disease controlling antirheumatic treatment were developed by a three stage Delphi process"}

These recommendations include lack of response to NSAIDs, and provide specific methods for evaluating persistent disease activity related to spinal disease, peripheral disease, and enthesitis. Both sets of recommendations for instituting DC-ART in AS require lack of efficacy to NSAIDs. This is clearly based on evidence that NSAIDs do work for symptom relief in almost half the patients. However, while the Canadian proposal leaves the decision about the use of anti-TNF $\alpha$ agents to the doctor and patient, the ASAS proposal provides specific measures to ascertain the need for these drugs. It certainly would be easier for funding agencies to evaluate suitability of patients for anti-TNF $\alpha$ treatment based on specific clinical information, rather than just rely on the doctor and patient decision to use a drug.

\section{LIMITATIONS TO THE ASAS PRELIMINARY RECOMMENDATIONS}

However, there are certain limitations to the ASAS preliminary set of recommendations. Although these recommendations are sensible, and therefore have face validity, they need to be tested for validity in clinical settings. In particular, the choice of cut off points for the individual measures which are set at a particular level (for example, > $40 \mathrm{~mm}$ on a visual analogue scale for some of the measures) is based on expert consensus, but without specific evidence that this level denotes active disease. The recommendations can be tested by evaluation of common cases of patients who have data on these measures, determination of whether a patient's disease is active or not by a number of expert clinicians, and analysis of the results by statistical methods. Alternatively, this information can be derived from drug trials where data have been collected and patients considered responders compared with those who failed to respond and those treated with placebo. The recent randomised trials with infliximab, etanercept, or leflunomide should provide baseline information for patients entering trials because they were performed before the dissemination of the ASAS group recommendations.

Although the ASAS recommendations may be appropriate for AS, they may not be as appropriate for the spondyloarthropathies such as psoriatic arthritis (PsA), or the arthritis of inflammatory bowel disease, where peripheral joint disease is a major component. For example, the use of the 44 joint count in PsA has not been validated.

Thus, the ASAS recommendations for the initiation of DC-ART in AS are a good start, and the group should be congratulated on their achievements to date. Hopefully the group will continue to work to improve the outcome for patients with AS.

\section{Ann Rheum Dis 2003;62:793-794}

\section{Author's affiliations}

D D Gladman, Centre for Prognosis Studies, Toronto W estern Hospital, ECW 5-034B,

Toronto, O N , Canada

Correspondence to: Dr D D Gladman; dafna.gladman@utoronto.ca

\section{REFEREN CES}

1 Gladman DD. Clinical aspects of spondyloarthropathies. Am J Med Sci 1998;316:234-8

2 Gran JT. An epidemiologic survey of the signs and symptoms of ankylosing spondylitis. Clin Rheumatol 1985;4:161-9.

3 Resnick D, N iyawama C. Ankylosing spondylitis. In: Resnick D, ed. Diagnosis of bone and joint disorders. 3rd ed. Philadelphia: Saunders, 1994:1008-74.

4 Cohen MD, G insurg W W. Late onset peripheral joint disease in ankylosing spondylitis. Arthritis Rheum 1983;26:186-90.
5 Carrett S, G raham D, Little H, Rubenstein I Rosen $P$. The natural disease course of ankylosing spondylitis. Arthritis Rheum 1993;26:186-90.

6 Resnick D. Radiology of seronegative spondyloarthropathies. Clin 0 rthop Relat Res $1979: 143: 38-45$

7 O'Neill TW, Bresnihan B. The heart in ankylosing spondylitis. Ann Rheum Dis 1992;51:705-6

8 Kraag G, Stokes B, G roh J, Helewa A, $\mathrm{G}$ oldsmith $\mathrm{CH}$. The effects of comprehensive home physiotherapy and supervision on patients with ankylosing spondylitis-an 8 -month followup. J Rheumatol $1994 ; 21: 261-3$

9 Dagfinrud H, Hagen K. Physiotherapy interventions for ankylosing spondylitis. Cochrane Database Syst Rev 2001:4:CD002822.

10 Miceli-Richard C, Dougados M. N SAIDs in ankylosing spondylitis. Clin Exp Rheumatol 2002; 20 (suppl 28):S65-6.

11 Ferraz MB, Tugwell P, G oldsmith CH, A tra E. $M$ eta-analysis of sulfasalazine in ankylosing spondylitis. I Rheumatol 1990:17:1482-6.

12 Clegg DO, Reda DJ, W eisman MH, Blackburn W D, Cush JJ, Cannon GW, et al. Comparison of sulfasalazine and placebo in the treatment of ankylosing spondylitis. Arthritis Rheum 1996;39:2004-12.

13 Maksymowych W, Inman RD, G ladman D, Thomson G, Stone M, Karsh J, et al. Canadian Rheumatology Association consensus on the use of anti-tumor necrosis factor-alpha directed therapies in the treatment of SpA. J Rheumatol 2003;30:1356-63.

14 Van den Bosch $F$, Kruithof $E$, Baeten $D$, Herssens A, De Keyser F, M ielants $H$, et al. Randomized double-blind comparison of chimeric monoclonal antibody to tumor necrosis factor alpha (infliximab) versus placebo in active spondyloarthropathy. Arthritis Rheum 2002;46:755-65.

15 Braun J, Brandt J, Listing J, Zink A, A Iten R, Golder W, et al. Treatment of active ankylosing spondylitis with infliximab: a randomized controlled multicentre trial. Lancet 2002;359:1187-93.

16 Stone M, Salonen D, Lax M, Payne U, Lapp $V$, Inman R. Clinical and imaging correlates of response to treatment with infliximab in patients with ankylosing spondylitis. J Rheumatol 2001;28:1605-14

17 Davis JC, van der Heijde D, Braun J, Dougados M, Cush JJ, Clegg DO, et al. Etanercept (Enbrel) improves signs and symptoms of ankylosing spondylitis: results of a phase 3 multicentre clinical trial [abstract]. Ann Rheum Dis 2003;62 (suppl 1):65

18 Braun J, Brandt J, Listing J, Rudwaleit M, Sieper J. Biologic therapies in the spondyloarthritis: new opportunities, new challenges. Curr 0 pin Rheumatol 2003;15:394-407.

19 Braun J, Pham T, Sieper J, Davis J, van der Linden Sj, Dougados M, et al. International ASAS consensus statement for the use of anti-tumour necrosis factor agents in patients with ankylosing spondylitis. Ann Rheum Dis 2003:62:817-24

20 Pham T, van der Heijde D, Calin A, Kham $M A$, van der Linden $S j$, Bellamy $N$, et al. Initiation of biological agents in patients with ankylosing spondylitis: results of a Delphi study by the ASAS Group. Ann Rheum Dis 2003;62:ar022873. 